\title{
A brief review: adipose-derived stem cells and their therapeutic potential in cardiovascular diseases
}

\author{
Teng $\mathrm{Ma}^{\dagger}$, Jiacheng Sun ${ }^{\dagger}$, Zhenao Zhao, Wei Lei, Yueqiu Chen, Xu Wang, Junjie Yang ${ }^{*}$ and Zhenya Shen ${ }^{*}$
}

\begin{abstract}
Adipose-derived stem cells (ADSCS) are easily obtained and expanded, and have emerged as a novel source of adult stem cells for the treatment of cardiovascular diseases. These cells have been shown to have the capability of differentiating into cardiomyocytes, vascular smooth muscle cells, and endothelial cells. Furthermore, ADSCs secrete a series of paracrine factors to promote neovascularization, reduce apoptosis, and inhibit fibrosis, which contributes to cardiac regeneration. As a novel therapy in the regenerative field, ADSCs still face various limitations, such as low survival and engraftment. Thus, engineering and pharmacological studies have been conducted to solve these problems. Investigations have moved into phase I and II clinical trials examining the safety and efficacy of ADSCs in the setting of myocardial infarction. In this review, we discuss the differentiation and paracrine functions of ADSCs, the strategies promoting their therapeutic efficacy, and their clinical usage.
\end{abstract}

Keywords: Adipose-derived stem cells, Stem cell transplantation, Cardiovascular diseases, Differentiation, Paracrine effect

\section{Background}

Cardiovascular diseases (CVDs) are the leading cause of morbidity and mortality worldwide [1]. Ischemic heart disease (IHD), specifically acute myocardial infarction (AMI), is the most common type of heart disease. The survival of patients with AMI has been substantially improved by advanced medical treatments and device-based therapies. The current medical therapies are capable of rescuing the remaining viable tissues within the damaged heart, while the problem is an inability to replace lost myocardium with regenerated cardiovascular cells [2]. Heart transplantation remains the only option for patients facing fatal heart failure, while the number of donors is limited. Stem cell transplantation is emerging as a promising strategy to regenerate the ischemic myocardium in such patients.

Stem cells, including embryonic stem cells (ESCs) and adult stem cells (ASCs), are cells capable of self-renewal and differentiation into a variety of phenotypes, and could

\footnotetext{
*Correspondence: jjyang@suda.edu.cn; uuzyshen@aliyun.com

${ }^{\dagger}$ Equal contributors

Department of Cardiovascular Surgery of the First Affiliated Hospital \& Institute for Cardiovascular Science, Soochow University, No.899, Pinghai Road, Suzhou 215006, China
}

be used for the treatment of heart failure [3, 4]. Recently, clinical trials using various ASCs for cardiac regeneration have been performed $[5,6]$. Bone marrow-derived mesenchymal stem cells (BM-MSCs) were the first to be recognized and the most extensively studied for CVDs [3]. However, harvesting of BM-MSCs is rather invasive and painful, with potential morbidity and low yields [7]. In contrast, obtaining adipose-derived stem cells (ADSCs) increases yields and reduces the pain in a simple procedure. Adipose tissue also has a significantly higher stem cell density than bone marrow (5\% versus $0.01 \%$ ) [7] .

ADSCs were first discovered and defined as mesenchymal stem cells (MSCs) isolated from processed lipoaspirate by Zuk and colleagues in 2001 [8]. These cells have the potential to differentiate into cardiovascular lineages, such as cardiomyocytes (CMs), endothelial cells (ECs), and vascular smooth muscle cells (VSMCs) [7]. Fan et al. demonstrated that ADSCs differentiate more quickly into ECs and possess a stronger proliferation ability than BM-MSCs [9]. Furthermore, Noël et al. observed a similar adipocyte differentiation ability of ADSCs compared to BM-MSCs, as well as less osteogenic and chondrogenic differentiation efficiency in ADSCs compared to BM-MSCs [10]. The paracrine effect of ADSCs appeared to play the major role in 
the treatment of IHDs. ADSCs could secrete various protective factors including vascular endothelial growth factor (VEGF), hepatocyte growth factor (HGF), insulin-like growth factor-1 (IGF-1), and a variety of microRNAs. Uysal et al. observed a similar VEGF level secreted by ADSCs and BM-MSCs [11], while Ikegame and colleagues indicated a greater production of VEGF and HGF by ADSCs than BM-MSCs [12]. Given these advantages, ADSCs may be better candidates for myocardial regeneration than bone marrow-derived stem cells.

However, stem cell-based transplantation therapy faces the problems of poor donor cell engraftment and survival in the ischemic heart. Because of the above limitation, researchers introduced several new strategies to enhance cell survival and retention. Increasing numbers of animal and clinical studies have focused on ADSCs and their therapeutic application in treating IHDs. In this review, we will focus on the regenerative role of ADSCs, the methods for therapeutic improvement, and their clinical application in CVD.

\section{Differentiation ability of ADSCs}

ADSCs play an important role in cardiovascular regeneration due to their ability to differentiate into a variety of cell lineages. Previous reports demonstrated that ADSCs were able to differentiate into CMs, ECs, and VSMCs, which are the main components of the cardiovascular system [13]. Various strategies of inducing ADSCs to differentiate into cardiovascular lineages were evaluated, such as application of biological reagents and genetic modification [2], which will be summarized in the following paragraphs (Fig. 1).

\section{Induction of ADSCs into cardiomyocytes}

ADSCs cultured in semi-solid methylcellulose medium spontaneously differentiated into cells with morphologic, molecular, and functional properties of CMs [14]. These CM-like cells expressed several cardiac-specific transcription factors, including GATA4, NKX2.5, MLC-2v, and MLC-2a, and displayed spontaneous and triggered action potentials. These beating clones comprised about $0.02 \%$ to $0.07 \%$ of CM-like cells at day 20 . This was the first description of the spontaneous differentiation of ADSCs into functional CM-like cells.

Various reagents have been used to induce the differentiation of ADSCs into cardiomyocytes, i.e., 5-azacytidine (5Aza), angiotensin II (Ang II) and transforming growth factor (TGF)- $\beta 1$. 5-Aza, an s-triazine nucleoside analogue of cytidine, was the first agent used for cardiomyogenic differentiation of bone marrow stromal cells [15]. Based on its inductive potential, Rangappa et al. [16] applied 5-Aza to ADSCs and successfully induced the differentiation of ADSCs into cardiomyocytes in vitro. After stimulated with 5-Aza, 20-30\% of cells showed binucleation and extended cytoplasmic processes with adjacent cells at 1 week. At 3 weeks, these cells began to beat spontaneously in culture. The differentiated ADSCs not only expressed cardiacspecific markers such as $\alpha$-actinin and troponin-I, but also exhibited biological and electrophysiological characteristics of CMs [16]. Ang II regulates myocardial functions and

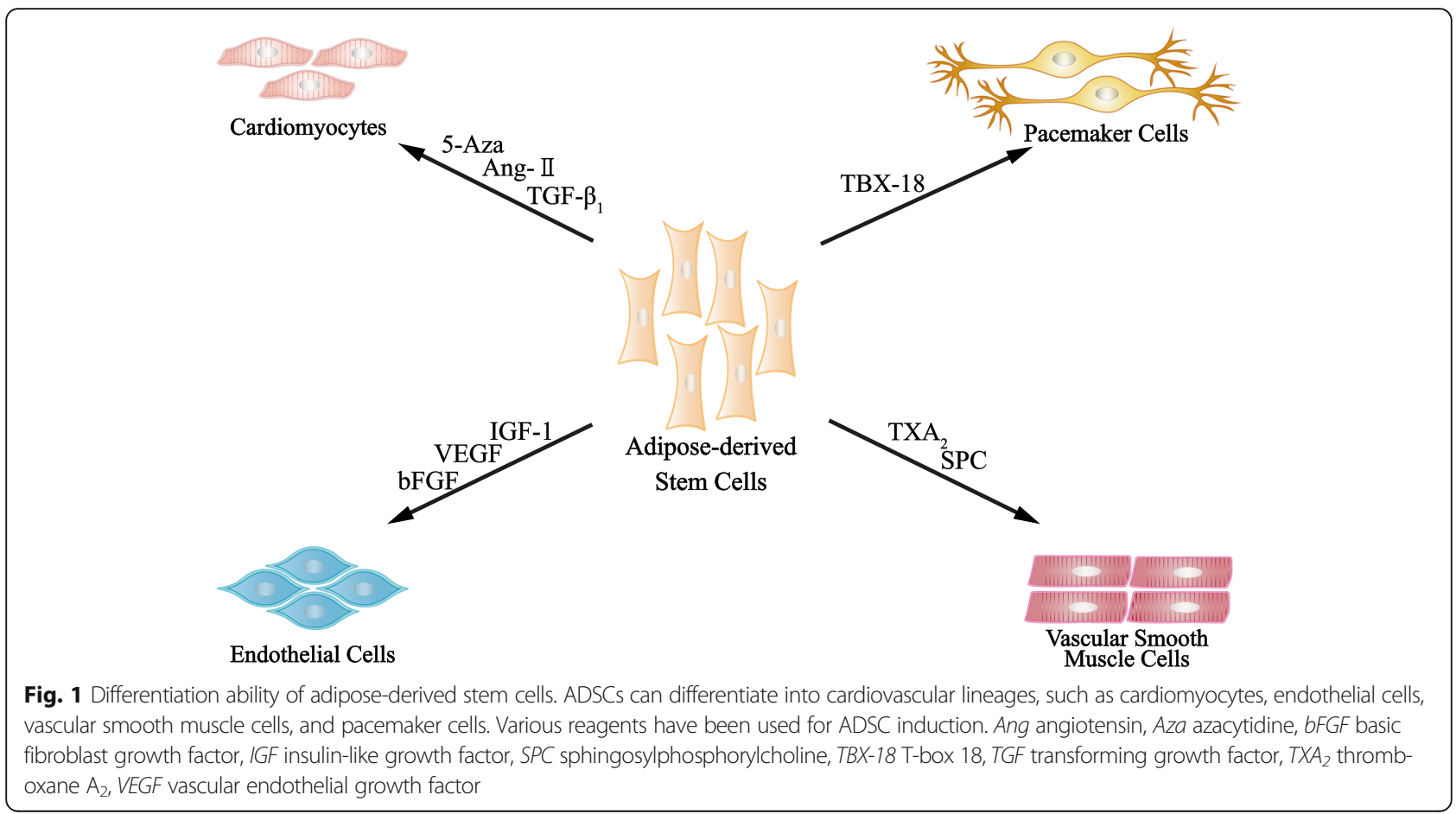


has various bioeffects [17]. Song et al. induced ADSCs with Ang II to differentiate into CMs characterized by cardiac troponin-I and connexin-43 expression [18]. Although Ang II had a lower inductive efficiency compared to 5-Aza ( $18 \%$ vs. $21 \%)$, it was nontoxic to the cells and could be a good substitution for 5-Aza. Moreover, Gwak et al. used TGF- $\beta 1$ to induce ADSCs to differentiate into CMs, as detected by immunofluorescence and flow cytometry [19].

Apart from these reagents, genetic modification of ADSCs has been used to induce their differentiation into cardiac pacemaker cells. TBX18, a T-box family member, is highly expressed in the progenitor cells of the sinoatrial node (SAN). Therefore, Yang et al. [20] transfected TBX18 to ADSCs, and the modified cells were capable of differentiating into pacemaker-like cells. TBX18 may enrich the efficiency of pacemaker-like cell differentiation by promoting the expression of pacemaker channel HCN4 [20].

\section{Induction of ADSCs into endothelial cells}

Endothelial dysfunction is common in conditions such as coronary artery disease, diabetes mellitus, and stroke [21, 22]. Stem cell transplantation-based therapeutic angiogenesis, including endothelial differentiation and paracrine effects, plays a key role in restoring endothelial function. The endothelial differentiation potential of ADSCs was first discovered in 2004 [23]. Several promising experiments indicated the differentiation capacity of ADSCs to ECs in vitro. Miranville et al. [23] demonstrated that a subset of ADSCs $\left(\mathrm{CD} 34^{+} / \mathrm{CD} 31^{-}\right)$was capable of differentiating into ECs when cultured in endothelial growth medium supplemented with IGF and VEGF. Under this condition, the cells showed a spindle-shaped morphology and high expression of EC markers such as CD31 and vWF. In contrast, Cao et al. [24] isolated another cell subset of ADSCs (CD34- / $\mathrm{CD} 31^{-}$) and cultured them on matrigel supplemented with basic fibroblast growth factor (bFGF) and VEGF. The characteristics of this subset were in accordance with human umbilical vein endothelial cells. Moreover, Konno et al. [25] emphasized bFGF to be an effective inducer of EC differentiation with an induction rate of more than $85 \%$. bFGF omission greatly diminished the ability of ADSCs to uptake Ac-LDL and downregulated EC marker expression, i.e., CD31, VE-Cadherin, vWF, VEGFR1, and eNOS. The in vivo differentiation potential of ADSCs into the endothelial lineage has also been demonstrated. Moon et al. [26] manifested the incorporation of ADSCs into the vasculature of mouse ischemic hindlimb and augmented capillary density after intravenous injection of the cells, which confirmed their EC differentiation capacity in vivo.

\section{Induction of ADSCs into VSMCs}

In addition to ECs and CMs, VSMCs are another important component of the cardiovascular system. In addition, VSMCs are critical for maintaining the physiological functions of the blood vessel wall. The characteristic markers of VSMCs are smooth muscle $\alpha$-actin (SM $\alpha$ actin), caldesmon, SM22, calponin, smooth muscle myosin heavy chain (SM-MHC), and smoothelin. Rodríguez et al. first reported the successful differentiation of ADSCs into SMCs in 2006 [27]. Cells were cultured in smooth muscle inductive medium consisting of MCDB131 and heparin for 6 weeks. These cells expressed VSMC markers and contracted in response to carbachol. Kim et al. [28] reported that U46619 (a thromboxane A2 analog) could induce differentiation of ADSCs to SMCs in vitro. ADSCs were treated with U46619 for 4 days, and these stimulated cells expressed VSMC-specific markers such as SM $\alpha$ actin, calponin, SM-MHC, and smoothelin, and exhibited increased contractility thereby providing another option for the induction of ADSCs to VSMCs. Furthermore, Jeon et al. observed that sphingosylphosphorylcholine could induce the differentiation of ADSCs into VSMCs via modulation of the Smad2 pathway [29].

\section{Paracrine effects of ADSCs}

Stem cell-based therapy shows great promise for regenerating damaged myocardium. ADSCs are currently the focus of considerable interest in the field of regenerative medicine and have been suggested as an ideal source for stem cellbased therapy. The recovery of cardiac function after cell transplantation is attributed to the paracrine effect rather than the direct differentiation of ADSCs [30]. In addition, ADSCs release different paracrine factors depending on the microenvironment. Under hypoxic condition, ADSCs secrete VEGF at a significantly higher level than under a normoxic condition [31]. Furthermore, ADSCs isolated from CAD or diabetic patients secrete a high level of HGF compared with healthy volunteers [32]. In this section, we summarize the paracrine effects of ADSCs (Fig. 2).

\section{Neovascularization}

Neovascularization is a multiple process involving arteriogenesis, vasculogenesis, and angiogenesis [33]. ADSCs could secrete a range of different growth factors and miRNAs in therapeutic neovascularization. Under hypoxic conditions, ADSCs secrete VEGF, a critical angiogenic factor, at a significantly high level. The transplantation of preconditioned ADSCs increased the capillary density and restored cardiac function of ischemic hearts [31]. ADSCderived miRNAs also play an important role in the process of neovascularization through promoting the proliferation and migration of ECs. Kang et al. reported that ADSCs promoted the migration of ECs by activating the miR-31/ hypoxia-inducible factor-1 (HIF-1) pathway [34]. Furthermore, Togliatto et al. [35] reported that the reduced expression of miR-126 in obese ADSCs inhibited the extracellular signal-regulated protein kinase 1/2/mitogenactivated protein kinase (Erk1/2/MAPK) pathway in the 


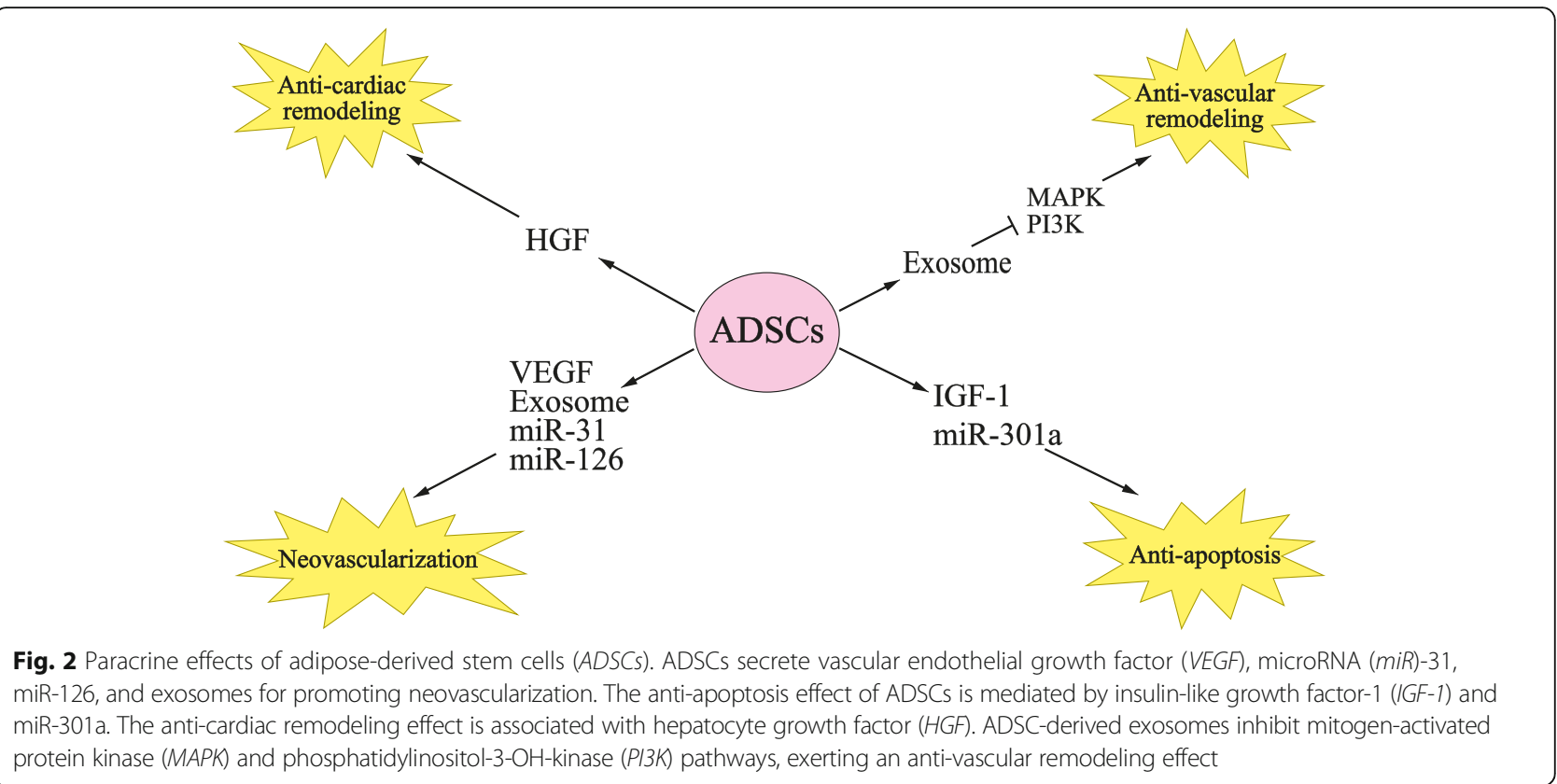

cells, which consequently led to impaired angiogenesis. In addition, they indicated that overexpressed miR-126 could restore the angiogenic ability of obese ADSCs.

\section{Anti-apoptosis}

Myocardial infarction leads to a progressive loss of cardiomyocytes, resulting in left ventricular remodeling and congestive heart failure. The anti-apoptotic effect of ADSCs is executed by the secreted mRNAs and miRNAs. IGF-1 secreted by ADSCs protects cardiac cells by activating both the phosphatidylinositol-3-OH-kinase (PI3K) and MEK1 signaling pathway [36]. Furthermore, ADSC-secreted miRNAs were reported to salvage ischemic myocardium and downregulate the apoptosis process, leading to a significant improvement in cardiac function after myocardial infarction [37]. Lee et al. [38] reported that overexpressed miRNA-301a in human ADSCs inhibited apoptosis signal-regulating kinase 1 (ASK1) expression. ASK1 was previously shown to have an important role in CM death, and thus inhibition of ASK1 by miR301a could promote the survival of injured CMs [38]. In addition, Salomone et al. indicated that ADSCs protected rats from acetaminophen-induced acute liver failure [39].

\section{Anti-cardiac and vascular remodeling}

Cardiac remodeling, characterized by cardiac hypertrophy and fibrosis, is a compensatory consequence of CVD and usually develops into heart failure. HGF is known as one of the main contributors to the antifibrosis function of ADSCs. In a preclinical swine model of myocardial ischemia and reperfusion injury, treatment with HGF attenuated cardiac hypertrophy, tissue fibrosis, and cardiac remodeling, and thus improved cardiac function [40].

Vascular remodeling is an adaptive reaction of the vessel to maintain constant flow. The progress involves hypertrophy, hyperplasia, and apoptosis of vascular cells as well as generation and degradation of extracellular matrix [41]. Liu et al. [42] observed that administration of exosomes from ADSCs significantly decreased intimal thickness in a mouse vein graft model. Moreover, this benefit effect was caused by decreased macrophage infiltration, attenuated inflammatory cytokine expression, and reduced activation of MAPK and PI3K signaling pathways [42].

\section{Engineered and pharmacologically modified ADSCS}

ADSCs have been shown to be an effective approach to ameliorating heart remodeling post-ischemia. The efficacy of stem cell therapies mostly depends on the survival and engraftment of the cells [43]. Different strategies have been introduced to promote their retention and engraftment after transplantation (Fig. 3).

\section{Engineered ADSCS}

Hamdi et al. [44] used scaffolds ensuring cell cohesiveness and co-delivery of implanted ADSCs; the engineered epicardial ADSC patches yielded less fibrosis (20.6\% vs. $28.6 \%)$, more angiogenesis in the infarct area of myocardial infarction, and a significantly better restoration of cardiac function. Moreover, magnetically iron-labeled ADSCs are another effective approach to overcome this limitation [45]. ADSCs preloaded with superparamagnetic iron oxide nanoparticles were transplanted in 


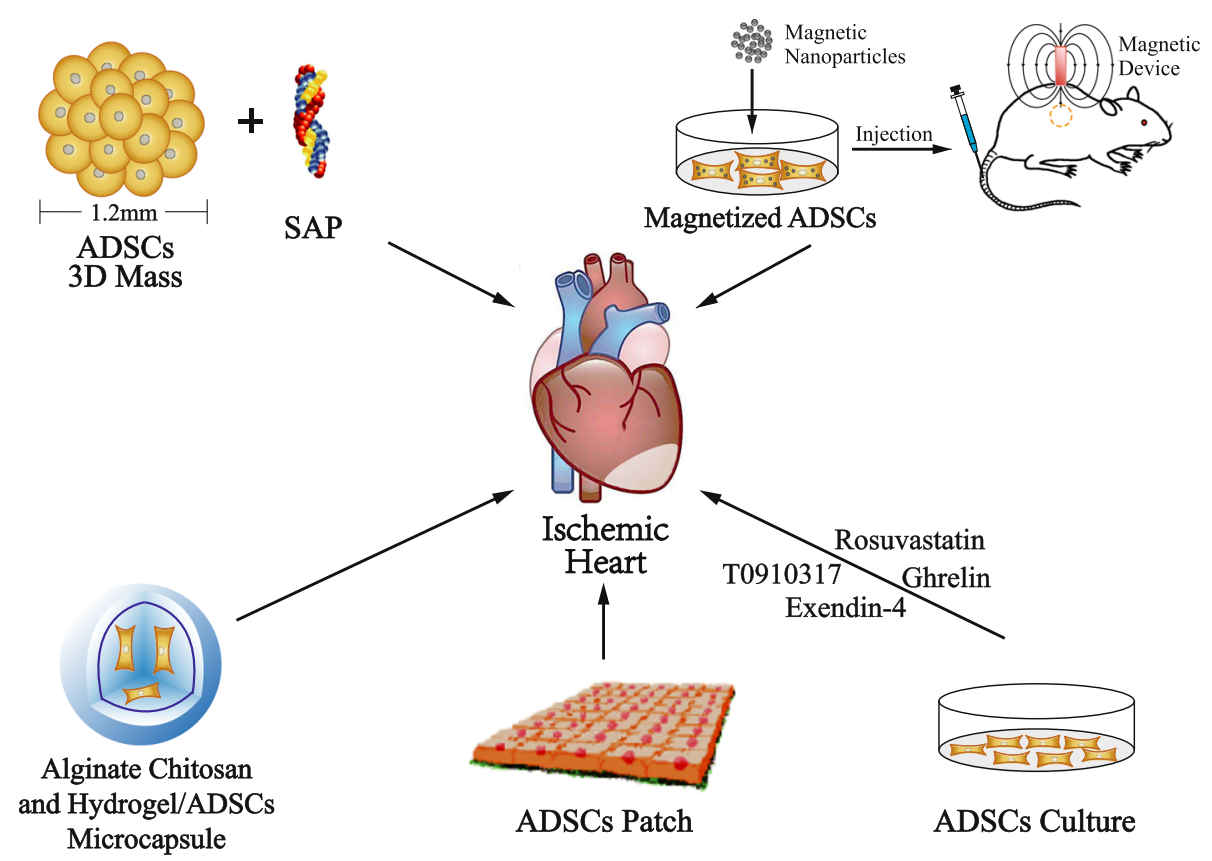

Fig. 3 Engineered and pharmacologically modified adipose-derived stem cells (ADSCS). A summary of engineering and pharmacological strategies for improving survival and retention of transplanted ADSCs in ischemic hearts is shown, such as three-dimensional (3D) cultured ADSCS combined with self-assembling peptide (SAP), magnetic nanoparticle-loaded ADSCs, encapsulated ADSCs with chitosan and hydrogel, ADSC patch, and pharmacologically modified ADSCS

infarct areas by intramyocardial injection. An externally applied static magnetic field significantly increased the number of localized "magnetic" cells, and thus markedly enhanced vascular density $\left(374.49 \pm 64.54\right.$ vessels $/ \mathrm{mm}^{2}$ vs. $197.67 \pm 60.70$ vessels $/ \mathrm{mm}^{2}$ ) and greatly decreased the percentage of apoptotic cardiomyocytes $(0.86 \% \pm 0.23 \%$ vs. $1.46 \% \pm 0.46 \%)$ in the treated group compared with controls. This study also revealed that magnetic nanoparticleloaded ADSCs enhanced heart function recovery after myocardial infarction, with the left ventricular ejection fraction (LVEF) elevated from $49.73 \% \pm 6.85 \%$ to $58.87 \% \pm$ $5.87 \%$ [45]. Microencapsulation of stem cells was used to increase the implanted ADSC retention in the infarcted myocardium. Paul et al. [46] and Follin et al. [47] encapsulated ADSCs with genipin-crosslinked alginate chitosan and cross-linked alginate hydrogel, respectively. The encapsulated ADSCs enhanced cell retention 3.5-fold, augmented vasculogenesis, and reduced fibrosis (infarct size: $21.6 \% \pm$ $1.1 \%$ vs. $27.2 \% \pm 3.1 \%$ ) and cardiac dysfunction (fractional shortening: $24.2 \% \pm 2.1 \%$ vs. $19.1 \% \pm 0.5 \%$ ) compared to free ADSCs in a myocardial infarction model. A recent study reported an interesting method for ADSC transplantation. Three-dimensional cell masses (3DCMs), a type of spheroid ADSC mass, have demonstrated their therapeutic effects on various ischemic diseases via increasing cell retention [48, 49]. Kim et al. [50] combined 3DCMs with selfassembling peptides (SAPs) to further promote their curative effects. This combinatorial therapy presented better survival and angiogenesis of ADSCs than transplantation with 3DCMs alone [50].

\section{Pharmacologically modified ADSCs}

Pharmacological treatment of ADSCs, with rosuvastatin [51], ghrelin [52], T0901317 [53], exendin-4 [54], S-nitroso$N$-acetyl-D,L-penicillamine (SNAP) [55], and NapFF-NO (FFGGG, and b-galactose caged nitric oxide) [56] etc., has increased the efficacy of ADSCs in promoting retention and the paracrine function of implanted cells. Rosuvastatin was used to promote the survival of ADSCs after transplantation into infarcted hearts. Zhang et al. [51] reported that rosuvastatin administration enhanced the viability and angiogenesis ability of ADSCs in a rat myocardial infarction model through the PI3K/Akt and MEK/ERK pathways [51]. Later, Han et al. found that ghrelin had an effect on ADSCs with a similar mechanism to rosuvastatin [52]. Wang et al. demonstrated that the liver $\mathrm{X}$ receptor (LXR) agonist T0901317 improved survival of ADSCs in infarcted hearts by modulating the TLR4/NF-kB and Keap-1/Nrf-2 signaling pathways [53]. Exendin-4 was reported to have the same beneficial effect as T0901317 on ADSCs [54]. Exendin-4 adjuvant therapy with ADCSs improved myocardial viability, and decreased oxidative stress and apoptosis by STAT3 activation through the phosphorylation of Akt and ERK1/2. In addition, exendin-4 could enhance the differentiation efficiency of ADSCs into CMs and VSMCs. This was associated with increased cardiac function and 
vascular density in the infarcted area [54]. Further research should be undertaken to elaborate the mechanism(s) of these protective effects.

\section{Clinical trials with ADSCs}

Convincing evidence from ADSC transplantation studies on cardiovascular disorders have prompted several clinical applications. Although still in phase I/II, ADSC transplantation therapy is expected to be widely used in the treatment of CVDs in the coming years. Moreover, various completed and ongoing clinical trials have been conducted to investigate the safety, feasibility, and efficacy of the application of ADSCs in patients with cardiovascular disorders (Table 1 ).

The first study, the APOLLO Trial (NCT00442806) [5] is a randomized, double-blind, placebo-controlled clinical trial of ADSCs in the treatment of patients with STelevation acute myocardial infarction. This trial evaluated the safety and feasibility of ADSCs delivered via intracoronary injections in a dose of $20-40$ million cells by major adverse cardiac and cerebral events (MACCE), magnetic resonance imaging (MRI), single-photon emission computed tomography (SPECT), and echocardiography. After
6 months of treatment, ADSCs promoted revascularization, improved the cardiac function, and reduced scar formation in the heart. The ATHENA trials I (NCT01556022) and II (NCT02052427) performed by Henry and colleagues focused on severe chronic myocardial infarction [6]. These trials are prospective trials with patients who are not eligible for percutaneous or surgical revascularization. The cells were delivered via an intramyocardial route. Results from the ATHENA trials were published recently; the processing and simultaneous delivery of ADSCs to patients with severe chronic ischemic cardiomyopathy was proved to elevate cardiac function and was accompanied by a remarkable improvement in the occluded blood perfusion. Kesten et al. carried out the ADVANCE study (NCT01216995), which involves 216 patients from 35 international clinical sites, aiming to investigate the efficacy of ADSC delivery on reducing infarct size. This trial is completed but its detailed data are not published yet.

All the above studies indicate that ADSC treatment could improve cardiac perfusion, reduce infarct size, and restore cardiac function after myocardial infarction. More importantly, all the completed clinical trials in Table 1 show a favorable safety profile and no tumor

Table 1 Completed and ongoing trials for heart disease using ADSCS

\begin{tabular}{|c|c|c|c|c|c|c|}
\hline $\begin{array}{l}\text { Clinicaltrials.gov } \\
\text { identifier }\end{array}$ & Study design & Disease type & Route of delivery & End-point & $\begin{array}{l}\text { Enrolled } \\
\text { number }\end{array}$ & Status \\
\hline NCT00442806 [5] & $\begin{array}{l}\text { Parallel assignment, } \\
\text { double-blind, phase I }\end{array}$ & $\begin{array}{l}\text { Acute myocardial } \\
\text { infarction }\end{array}$ & $\begin{array}{l}\text { Intracoronary } \\
\text { injection }\end{array}$ & Safety, cardiac function & 48 & Completed \\
\hline NCT01502501 & $\begin{array}{l}\text { Single group assignment, } \\
\text { open-label, phase I, phase II }\end{array}$ & $\begin{array}{l}\text { Congestive heart } \\
\text { failure }\end{array}$ & $\begin{array}{l}\text { Intramyocardial/ } \\
\text { intravenous } \\
\text { injection }\end{array}$ & $\begin{array}{l}\text { 6-minute walk test, } \\
\text { LVEF, NYHA class }\end{array}$ & 10 & Recruiting \\
\hline NCT02673164 & $\begin{array}{l}\text { Parallel assignment, } \\
\text { double-blind, phase ॥ }\end{array}$ & Heart failure & $\begin{array}{l}\text { Intramyocardial } \\
\text { injection }\end{array}$ & Safety, LVESV & 138 & Not recruiting \\
\hline NCT00426868 & $\begin{array}{l}\text { Parallel assignment, } \\
\text { double-blind, phase I }\end{array}$ & Ischemic myocardium & $\begin{array}{l}\text { Intramyocardial } \\
\text { injection }\end{array}$ & Safety, cardiac function & 36 & Completed \\
\hline NCT01502514 & $\begin{array}{l}\text { Single group assignment, } \\
\text { open-label, phase I, phase II }\end{array}$ & $\begin{array}{l}\text { Congestive Heart } \\
\text { Failure }\end{array}$ & $\begin{array}{l}\text { Intramyocardial/ } \\
\text { intravenous } \\
\text { injection }\end{array}$ & $\begin{array}{l}\text { 6-minute walk test, } \\
\text { LVEF, NYHA class }\end{array}$ & 10 & Recruiting \\
\hline NCT02387723 & $\begin{array}{l}\text { Single group assignment, } \\
\text { open-label, phase I }\end{array}$ & Heart failure & $\begin{array}{l}\text { Intramyocardial } \\
\text { injection }\end{array}$ & Safety, LVESV, LVEF & 10 & Completed \\
\hline NCT01449032 & $\begin{array}{l}\text { Parallel assignment, } \\
\text { double-blind, phase ॥ }\end{array}$ & Chronic heart failure & $\begin{array}{l}\text { Intramyocardial } \\
\text { injection }\end{array}$ & Exercise test & 60 & $\begin{array}{l}\text { Active, not } \\
\text { recruiting }\end{array}$ \\
\hline NCT02052427 [6] & $\begin{array}{l}\text { Parallel assignment, } \\
\text { double-blind, phase ॥ }\end{array}$ & $\begin{array}{l}\text { Chronic myocardial } \\
\text { ischemia }\end{array}$ & $\begin{array}{l}\text { Intramyocardial } \\
\text { injection }\end{array}$ & $\begin{array}{l}\text { Change in Minnesota } \\
\text { Living with Heart } \\
\text { Failure Questionnaire }\end{array}$ & 45 & completed \\
\hline NCT01556022 [6] & $\begin{array}{l}\text { Parallel assignment, } \\
\text { double-blind, phase II }\end{array}$ & $\begin{array}{l}\text { Chronic myocardial } \\
\text { ischemia }\end{array}$ & $\begin{array}{l}\text { Intramyocardial } \\
\text { injection }\end{array}$ & Safety, cardiac function & 45 & completed \\
\hline NCT01709279 & $\begin{array}{l}\text { Single group assignment, } \\
\text { open-label, phase I }\end{array}$ & Ischemic heart failure & Intracoronary & All cause harmful events & 6 & Recruiting \\
\hline NCT01974128 & $\begin{array}{l}\text { Single group assignment, } \\
\text { open-label, phase I, phase II }\end{array}$ & $\begin{array}{l}\text { Acute myocardial } \\
\text { infarction }\end{array}$ & $\begin{array}{l}\text { Intramyocardial } \\
\text { injection }\end{array}$ & Cardiac Improvement & 10 & Not recruiting \\
\hline NCT01216995 & $\begin{array}{l}\text { Parallel assignment, } \\
\text { double-blind, phase ॥ }\end{array}$ & $\begin{array}{l}\text { Acute myocardial } \\
\text { infarction }\end{array}$ & $\begin{array}{l}\text { Intracoronary } \\
\text { injection }\end{array}$ & $\begin{array}{l}\text { Reduction in infarct size, } \\
\text { MACCE rates }\end{array}$ & 216 & completed \\
\hline
\end{tabular}


development with ADSC transplantation. However, Pendleton and colleagues found that ADSCs could develop into glioma in vitro [57]. In accordance with the study of Pendleton et al., Ra et al. [58] observed tumor development in nude mice 26 weeks after ADSC transplantation at the dose of $2 \times 10^{8}$ cells $/ \mathrm{kg}$ body weight, with no tumor induction at a lesser dose [58]. In addition, systematic ADSC application still faces some potential risks such as embolism and inflammation. In chronic cardiovascular diseases, the progressing apoptosis of cardiomyocytes and fibrosis play key roles in heart remodeling. The reversal of heart remodeling requires a lot of cardiomyocytes to replace the lost cells and fibrous tissue. However, due to the limited differentiation ability of ADSCs into cardiomyocytes, the cell transplantation may lead to a relatively poor therapeutic outcome. More clinical trials based on ADSC transplantation are expected in the near future.

\section{Conclusion}

ADSCs are easily obtained and expanded, and are ideal candidates for cell-based therapy. The differentiation of ADSCs into CMs, ECs, and VSMCs has been induced by various reagents, growth factors, and genetic modification. In addition, ADSCs play an important role in antiapoptosis, anti-cardiac remodeling, and angiogenesis through their paracrine effects. Despite the above regenerative characteristics, ADSCs face the major challenge of low survival and retention in the harsh ischemic microenvironment. Therefore, researchers have utilized engineering and pharmacological strategies to overcome theses difficulties. In animal models, ADSCs have been confirmed as an effective therapy for CVD. Treatment with ADSCs reduced infarct size and enhanced cardiac function through direct differentiation and paracrine effects. Phase I/II clinical trials have been conducted to test the safety and feasibility of ADSC therapy. Further phase III clinical trials are needed to achieve more reliable and efficient benefits. Although there are still many problems to solve, ADSC transplantation could be a promising means of treating cardiovascular disease in the near future.

\footnotetext{
Abbreviations

3DCM: Three-dimensional cell mass; 5-Aza: 5-Azacytidine; ADSC: Adipose-derived stem cell; ADVANCE: A Phase II Trial of Safety and Efficacy of ADRCs Delivered Via the Intracoronary Route in the Treatment of Patients With ST-elevation Acute Myocardial Infarction; AMI: Acute myocardial infarction; Ang II: Angiotensin II; APOLLO: A Randomized Clinical Trial of AdiPOse-derived Stem ceLLs in the Treatment of Patients With ST-elevation myOcardial Infarction; ASC: Adult stem cell; ASK1: Apoptosis signal-regulating kinase 1; ATHENA: Adipose-derived Regenerative Cells in the Treatment of Patients With Chronic Ischemic Heart Disease Not Amenable to Surgical or Interventional Revascularization; bFGF: Basic fibroblast growth factor; BM-MSC: Bone marrow-derived mesenchymal stem cell; CM: Cardiomyocyte; CVD: Cardiovascular disease; EC: Endothelial cell; ERK1/ 2: Extracellular signal-regulated protein kinase 1/2; ESC: Embryonic stem cell; HCN4: Hyper-polarization activated cyclic nucleotide gated potassium channel 4; HGF: Hepatocyte growth factor; HIF-1: Hypoxia-inducible
}

factor-1; IGF-1: Insulin-like growth factor-1; IHD: Ischemic heart disease; LVEF: Left ventricular ejection fraction; LXR: Liver X receptor; MACCE: Major adverse cardiac and cerebral events; MAPK: Mitogen-activated protein kinase; MEK1: Mitogen-activated protein kinase 1; MRI: Magnetic resonance imaging; MSC: Mesenchymal stem cell; PI3K: Phosphatidylinositol-3-OH-kinase;

SAN: Sinoatrial node; SAP: Self-assembling peptides; SM a-actin: Smooth muscle a-actin; SM-MHC: Smooth muscle myosin heavy chain; SPECT: Single-photon emission computed tomography; TGF: Transforming growth factor;

VEGF: Vascular endothelial growth factor; VSMC: Vascular smooth muscle cell

\section{Acknowledgements}

Not applicable.

\section{Funding}

This work was supported by the National Natural Science Foundation of China (No. 81400199 and 81600218), Natural Science Foundation of Jiangsu Province (No. BK20150321 and BK20150320), Suzhou Municipal Science and Technology Foundation (No. SYS201414, SYS201540, and SYS201675) and Natural Science Foundation for Colleges and Universities in Jiangsu Province (No. 15KJB180017).

\section{Availability of data and materials}

Not applicable.

\section{Authors' contributions}

$J Y$ and ZS are responsible for the concept of the review. TM and JS were responsible for writing the first draft of the manuscript. $Z Z, W L, Y C$, and $X W$ were responsible for critical review of the manuscript. All authors read and approved the final manuscript.

\section{Competing interests}

The authors declare that they have no competing interests.

\section{Consent for publication}

We confirm the tables and figure in the manuscript are original for this article.

Ethical approval and consent to participate

Not applicable.

\section{Publisher's Note}

Springer Nature remains neutral with regard to jurisdictional claims in published maps and institutional affiliations.

Published online: 05 June 2017

\section{References}

1. Finegold JA, Asaria P, Francis DP. Mortality from ischaemic heart disease by country, region, and age: statistics from World Health Organization and United Nations. Int J Cardiol. 2013;168(2):934-45.

2. Ji ST, et al. Promising therapeutic strategies for mesenchymal stem cellbased cardiovascular regeneration: from cell priming to tissue engineering. Stem Cells Int. 2017;2017:3945403.

3. Orlic D, Hill JM, Arai AE. Stem cells for myocardial regeneration. Circ Res. 2002;91(12):1092-102.

4. Dimmeler S, Zeiher AM. Wanted! The best cell for cardiac regeneration. J Am Coll Cardiol. 2004;44(2):464-6.

5. Houtgraaf $\mathrm{JH}$, et al. First experience in humans using adipose tissue-derived regenerative cells in the treatment of patients with ST-segment elevation myocardial infarction. J Am Coll Cardiol. 2012;59(5):539-40.

6. Henry TD, et al. The Athena trials: autologous adipose-derived regenerative cells for refractory chronic myocardial ischemia with left ventricular dysfunction. Catheter Cardiovasc Interv. 2017;89(2):169-77.

7. Fraser JK, et al. Fat tissue: an underappreciated source of stem cells for biotechnology. Trends Biotechnol. 2006;24(4):150-4.

8. Zuk PA, et al. Multilineage cells from human adipose tissue: implications for cell-based therapies. Tissue Eng. 2001;7(2):211-28.

9. Fan $\sqcup$, et al. Comparison of endothelial differentiation capacity of adiposederived stem cells and bone marrow mesenchymal stem cells from rats. Nan Fang Yi Ke Da Xue Xue Bao. 2016;36(9):1247-54. 
10. Noel D, et al. Cell specific differences between human adipose-derived and mesenchymal-stromal cells despite similar differentiation potentials. Exp Cell Res. 2008;314(7):1575-84.

11. Uysal CA, et al. The effect of bone-marrow-derived stem cells and adiposederived stem cells on wound contraction and epithelization. Adv Wound Care (New Rochelle). 2014;3(6):405-13.

12. Ikegame $Y$, et al. Comparison of mesenchymal stem cells from adipose tissue and bone marrow for ischemic stroke therapy. Cytotherapy. 2011; 13(6):675-85.

13. Planat-Benard $V$, et al. Plasticity of human adipose lineage cells toward endothelial cells: physiological and therapeutic perspectives. Circulation. 2004;109(5):656-63.

14. Planat-Benard V, et al. Spontaneous cardiomyocyte differentiation from adipose tissue stroma cells. Circ Res. 2004;94(2):223-9.

15. Makino S, et al. Cardiomyocytes can be generated from marrow stromal cells in vitro. J Clin Invest. 1999;103(5):697-705.

16. Rangappa S, et al. Transformation of adult mesenchymal stem cells isolated from the fatty tissue into cardiomyocytes. Ann Thorac Surg. 2003;75(3):775-9.

17. Weber KT. Fibrosis, a common pathway to organ failure: angiotensin II and tissue repair. Semin Nephrol. 1997;17(5):467-91.

18. Song $\mathrm{K}$, et al. In vitro culture, determination, and directed differentiation of adult adipose-derived stem cells towards cardiomyocyte-like cells induced by angiotensin II. Appl Biochem Biotechnol. 2013;170(2):459-70.

19. Gwak SJ, et al. In vitro cardiomyogenic differentiation of adipose-derived stromal cells using transforming growth factor-beta1. Cell Biochem Funct. 2009;27(3):148-54

20. Yang M, et al. TBX18 gene induces adipose-derived stem cells to differentiate into pacemaker-like cells in the myocardial microenvironment. Int J Mol Med. 2016;38(5):1403-10.

21. Hartge MM, Unger $T$, Kintscher U. The endothelium and vascular inflammation in diabetes. Diab Vasc Dis Res. 2007;4(2):84-8.

22. Slevin $\mathrm{M}$, et al. Can angiogenesis be exploited to improve stroke outcome? Mechanisms and therapeutic potential. Clin Sci (Lond). 2006;111(3):171-83.

23. Miranville $\mathrm{A}$, et al. Improvement of postnatal neovascularization by human adipose tissue-derived stem cells. Circulation. 2004;110(3):349-55.

24. Cao $Y$, et al. Human adipose tissue-derived stem cells differentiate into endothelial cells in vitro and improve postnatal neovascularization in vivo. Biochem Biophys Res Commun. 2005;332(2):370-9.

25. Konno $M$, et al. Adipose-derived mesenchymal stem cells and regenerative medicine. Dev Growth Differ. 2013:55(3):309-18.

26. Moon $\mathrm{MH}$, et al. Human adipose tissue-derived mesenchymal stem cells improve postnatal neovascularization in a mouse model of hindlimb ischemia. Cell Physiol Biochem. 2006;17(5-6):279-90.

27. Rodriguez LV, et al. Clonogenic multipotent stem cells in human adipose tissue differentiate into functional smooth muscle cells. Proc Natl Acad Sci U S A. 2006;103(32):12167-72.

28. Kim MR, et al. Thromboxane A(2) induces differentiation of human mesenchymal stem cells to smooth muscle-like cells. Stem Cells. 2009;27(1):191-9.

29. Jeon ES, et al. Sphingosylphosphorylcholine induces differentiation of human mesenchymal stem cells into smooth-muscle-like cells through a TGF-beta-dependent mechanism. J Cell Sci. 2006:119(Pt 23):4994-5005.

30. Haider $\mathrm{H}$, et al. IGF-1-overexpressing mesenchymal stem cells accelerate bone marrow stem cell mobilization via paracrine activation of SDF-1alpha/CXCR4 signaling to promote myocardial repair. Circ Res. 2008;103(11):1300-8.

31. Banai $\mathrm{S}$, et al. Angiogenic-induced enhancement of collateral blood flow to ischemic myocardium by vascular endothelial growth factor in dogs. Circulation. 1994;89(5):2183-9.

32. Dzhoyashvili NA, et al. Disturbed angiogenic activity of adipose-derived stromal cells obtained from patients with coronary artery disease and diabetes mellitus type 2. J Transl Med. 2014;12:337.

33. Wen Z, et al. Bone marrow mesenchymal stem cells for post-myocardial infarction cardiac repair: microRNAs as novel regulators. J Cell Mol Med. 2012;16(4):657-71.

34. Kang T, et al. Adipose-derived stem cells induce angiogenesis via microvesicle transport of miRNA-31. Stem Cells Transl Med. 2016;5(4):440-50

35. Togliatto $G$, et al. Obesity reduces the pro-angiogenic potential of adipose tissue stem cell-derived extracellular vesicles (EVs) by impairing miR-126 content: impact on clinical applications. Int J Obes (Lond). 2016;40(1):102-11.

36. Mehrhof FB, et al. In cardiomyocyte hypoxia, insulin-like growth factor-linduced antiapoptotic signaling requires phosphatidylinositol-3-OH-kinasedependent and mitogen-activated protein kinase-dependent activation of the transcription factor CAMP response element-binding protein. Circulation. 2001;104(17):2088-94

37. Wang, K., et al., Enhanced cardioprotection by human endometrium mesenchymal stem cells driven by exosomal microRNA-21. Stem Cells Transl Med. 2017;6(1):209-22

38. Lee CY, et al. MicroRNA-mediated down-regulation of apoptosis signal-regulating kinase 1 (ASK1) attenuates the apoptosis of human mesenchymal stem cells (MSCS) transplanted into infarcted heart. Int J Mol Sci. 2016;17(10):1752.

39. Salomone F, et al. Efficacy of adipose tissue-mesenchymal stem cell transplantation in rats with acetaminophen liver injury. Stem Cell Res. 2013;11(3):1037-44.

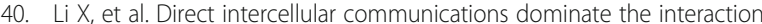
between adipose-derived MSCs and myofibroblasts against cardiac fibrosis. Protein Cell. 2015;6(10):735-45.

41. Dzau VJ, Gibbons GH. Vascular remodeling: mechanisms and implications. J Cardiovasc Pharmacol. 1993;21 Suppl 1:S1-5.

42. Liu $R$, et al. Extracellular vesicles derived from adipose mesenchymal stem cells regulate the phenotype of smooth muscle cells to limit intimal hyperplasia. Cardiovasc Drugs Ther. 2016;30(2):111-8.

43. Chen $L$, et al. Application of adipose-derived stem cells in heart disease. J Cardiovasc Transl Res. 2014;7(7):651-63.

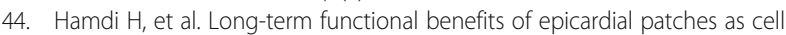
carriers. Cell Transplant. 2014:23(1):87-96.

45. Wang J, et al. Externally applied static magnetic field enhances cardiac retention and functional benefit of magnetically iron-labeled adipose-derived stem cells in infarcted hearts. Stem Cells Transl Med. 2016;5(10):1380-93.

46. Paul A, et al. Genipin-cross-linked microencapsulated human adipose stem cells augment transplant retention resulting in attenuation of chronically infarcted rat heart fibrosis and cardiac dysfunction. Cell Transplant. 2012; 21(12):2735-51.

47. Follin B, et al. Human adipose-derived stromal cells in a clinically applicable injectable alginate hydrogel: phenotypic and immunomodulatory evaluation. Cytotherapy. 2015;17(8):1104-18.

48. Kang JM, et al. Adhesion and differentiation of adipose-derived stem cells on a substrate with immobilized fibroblast growth factor. Acta Biomater. 2012;8(5):1759-67.

49. Kim JH, et al. Stem cell recruitment and angiogenesis of neuropeptide substance $P$ coupled with self-assembling peptide nanofiber in a mouse hind limb ischemia model. Biomaterials. 2013;34(6):1657-68.

50. Kim JH, et al. Combinatorial therapy with three-dimensionally cultured adipose-derived stromal cells and self-assembling peptides to enhance angiogenesis and preserve cardiac function in infarcted hearts. J Tissue Eng Regen Med. 2016. doi:10.1002/term.2181.

51. Zhang $Z$, et al. Rosuvastatin enhances the therapeutic efficacy of adiposederived mesenchymal stem cells for myocardial infarction via PI3K/Akt and MEK/ERK pathways. Basic Res Cardiol. 2013;108(2):333.

52. Han D, et al. Ghrelin improves functional survival of engrafted adiposederived mesenchymal stem cells in ischemic heart through PI3K/Akt signaling pathway. Biomed Res Int. 2015;2015:858349.

53. Wang $Y$, et al. Activation of liver $X$ receptor improves viability of adiposederived mesenchymal stem cells to attenuate myocardial ischemia injury through TLR4/NF-kappaB and Keap-1/Nrf-2 signaling pathways. Antioxid Redox Signal. 2014;21(18):2543-57.

54. Liu J, et al. The stem cell adjuvant with Exendin-4 repairs the heart after myocardial infarction via STAT3 activation. J Cell Mol Med. 2014;18(7):1381-91.

55. Berardi GR, et al. Transplantation of SNAP-treated adipose tissue-derived stem cells improves cardiac function and induces neovascularization after myocardium infarct in rats. Exp Mol Pathol. 2011:90(2):149-56.

56. Yao $X$, et al. Nitric oxide releasing hydrogel enhances the therapeutic efficacy of mesenchymal stem cells for myocardial infarction. Biomaterials. 2015;60:130-40

57. Pendleton C, et al. Mesenchymal stem cells derived from adipose tissue vs bone marrow: in vitro comparison of their tropism towards gliomas. PLoS One. 2013:8(3):e58198.

58. Ra JC, et al. Safety of intravenous infusion of human adipose tissue-derived mesenchymal stem cells in animals and humans. Stem Cells Dev. 2011;20(8): 1297-308 